\title{
استخدام علم هصر في عمل تصميمات لزي قوهي يعبر عن هويتنا داخل وخارج هصر
}

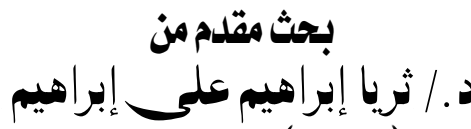 \\ (مدربس) بقسم الموضيم فيمية \\ أكاديمية ألفن والتصميم الموضيم \\ المعهد العالي للفنون التطبيقية التمنية \\ بالسأدس من أكتوبر التطبية
}

مجلة بحوث التربية النوعية - جامعة المنصورة

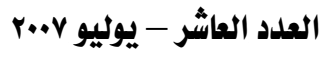




\section{استخدام علم هصر في عمل تصميسمات للزي قوهي}

\section{يعبر عن هويتنا داخل وخارة هصر}

د ـ / ثريا إبراهيم علك إبراهيم

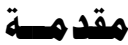

الزي على مر العصور حصيلة شعب له سماته، وخصائصده التي تعبر عن هويته، والتي تميزه.

وأن المحافظة على مظاهر الشعب بملبسـه جـزء مـن أحيـاء تراثه لأنه يحـافظ على هويـة وطن أو دولـة تعبر عن تاريخ مُشرف، له علاقة بالحياة التي ترتبط بظروف البيئة. كما أن الزي يعبر ويملـك هويـة جسدية، ويبعث رسالة خاصة للآخرين هـا بجانب إنه يخاطب مشاعر الفـرد بـاعتبـاره مقومـا أسـاسياً وأصيلاً ِِِ مجال الثقافة. قال تعالي : " يـا أيها الناس إن خلقناكهم من ذكر وأنثى وجعلناكهم شعوباً

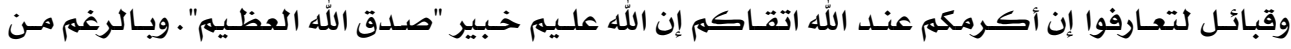
دخـول فنـون الموضــة إلا أن أزيــاء الـشعوب تحهـل رمــوزا متوارثــة تعـبر عـن الــذات العربيــة أمــام الثقافة العالمية.

\section{مشكلة البحث وأهميميته :}

يتناول البحث قضية هامـة وهي أن مصر ليس لها زي قومي يعبر عن الهويـة المصريـة بالمقارنـة

بباقي الشعوب. وان مصر يغزوها الآن أزياء بتصميمات، وألوان، لا تحمل ولا تشير من قريب أو من بعيد إلى الهوية المصرية بل تطلق عليها مقدمـة البحث "فوضى الزي وأن تلك التصميمات الفوضويـة قد غزت الأسواق، والثقافة المصرية بصفة عامـة، والشباب بصفة خاصدة. لـذا تم اختيـار علسم مصر يْ عمل تصميمات زي قومي يعبر عن الهوية المصرية لبعض المهن والفئات التي تمثل مصر يِّ الداخل والخـارج.

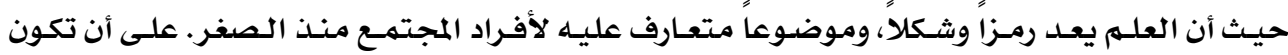

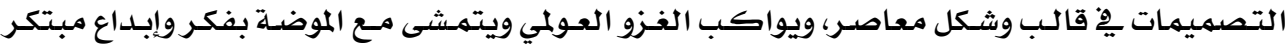
مبسط. بشكل جديد متطور بقيه جمالية. أهمية البحث : ترجـع أهمية البـحث ِِِ عهل زي قومي يعبر عن هويتنـا حيـث أن لكل بلــ زي متعـارف عليـه

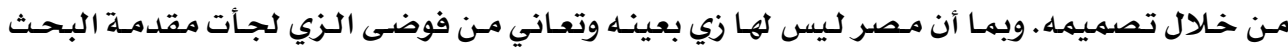

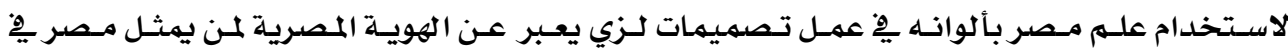

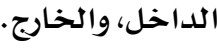


ظهـرت مهارة المرأة ِِّ مجتمـع الريـ والبـدو على مستوى جميـع المحافظـات فِّ زخرفة الأزياء بتصميمات ورسوم غاية من الجمال والتي بـدورها حكت هويـة شعب له جـذوره التراثيـة،

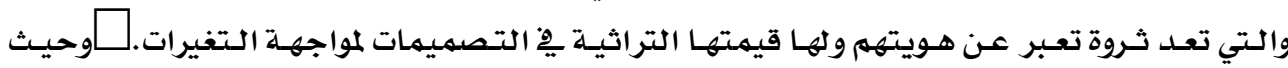

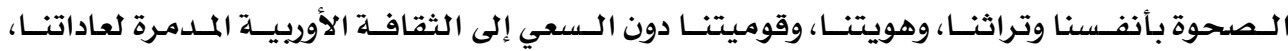

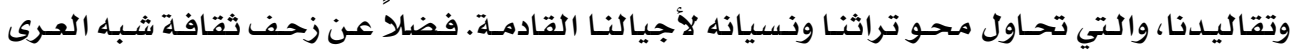

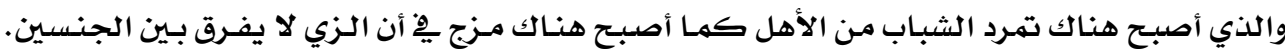
مما يشكل خطورة تتمثل يِّ إلغاء هوية وشخصية الفرد والتخلي عن تراثه.

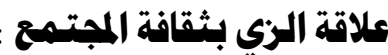

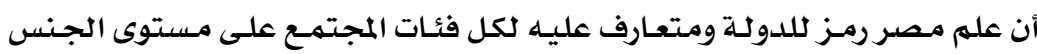

والعمـر، والطبقـة، والمكانـة الاجتماعيـة، والوظيفيـة، والثقافيـة، والسياسية، فهنـاك ارتبـاط بـين العلهم بألوانه وحياة الإنسان ببيئته خاصـة إذا كانت جذوروه تقف على جوانب عديدة مـن عادات، وتقاليد،

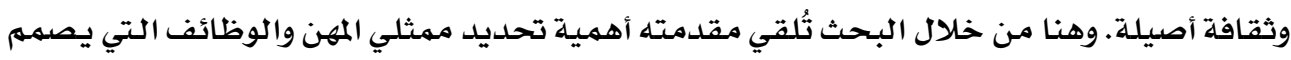
لها الزي فهم واجهة المجتمع من الداخل والخارج.وأن تصميم الزي مـن علهم مصر يكشف عن أنهاط الجانب الإبداعي على مستوى الشعوب - ويعد الواجهة كوسيلة للاتصال على مستوى العـالم والتي تعبر عن الهوية المصرية باعتبارهـا ثقافة مجتهـع يواجـه حرب الثقافات ومظهر مـن مظاهر القوميـة التي تصور شخصية الشعب.

\section{المبررات والأسباب التي دعت الباحثة لعمل زي هصري التعب}

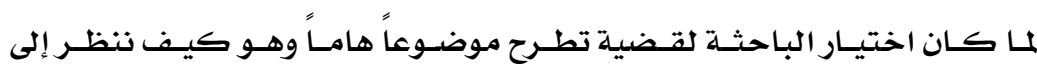

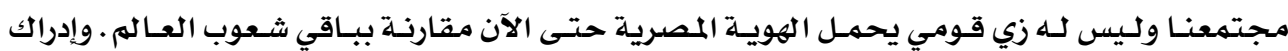

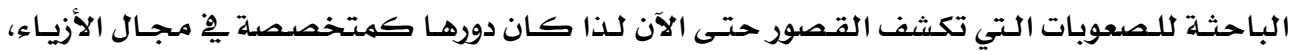

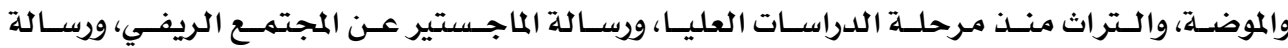
الدكتوراه عن المجتمع البدوي، فقد شغلتها الفكرة عن عمل زي يعبر عن هويتنا حيث مرت بالآتي :

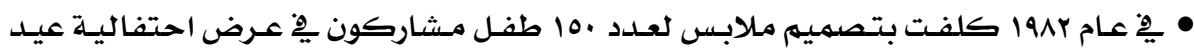
العمال أمام رئيس الجمهورية ولا تجد سوى تصميم بدلة العمال وارتدت الباحثة علم مصر.

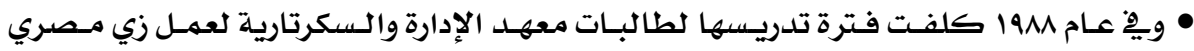
لعـروض فرقة الفنون الشعبية مـن الطالبـات، لكن تصميم الملابس كان مـن الريف والبدو 


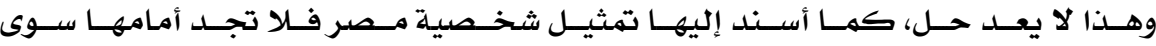

$$
\text { الزي الفلاحي. }
$$

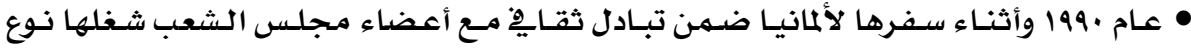
الهدايا فلا تجد غير تكليف أحسد المصانع بالمحلـة الكبرى لطبـع عدد مـن الايشاريات وكتب عليها مـصرواستخخدمتها الباحثـة والمرأة الألمانيـة إيشارب على الشعر واستخلدمها الرجـال

$$
\text { جرافت على عنق الرقبـة. }
$$

ومن خلال تدريسها لمادة الأزياء لكلا مـن الفنـون المسرحية ومعهد السينهما ومعهد الفنـون التطبيقيـة وكليـة الآداب مسـرح، هـذا بخـلاف اللقـاءات التليفزيونيـة والإذاعيـة، ومـا نشر مـن مقـالات لوسائل الأعلام كان يشغلها أن مصر ليس لها زي قومي يعبر عن الهوية المصريـة. وعندما شـاركت ِِّ

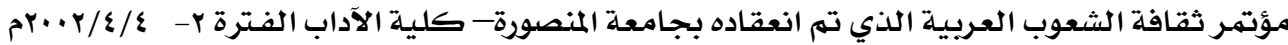
شـاركت ببحث : التعـرف على ثقافة الشعوب العربيـة مـن خـلال الزي فِ الماضـي والحاضـر . وحيـث أن مصر لـيس لـديها زي قومي وأن الـزي الريفي والبـدوي وأزيـاء المحافظـات خاصسة بثقافـات مجتمعـات.

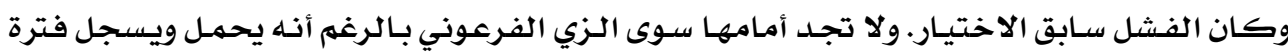
تاريخية ولا يصلح أن يكون زي قومي. لذا كان موضوع البحث هـو الشغل الشاغل للباحثة يِّاختيار

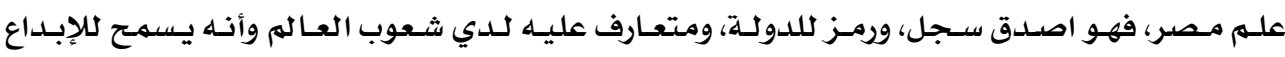
والاستلهام والاستمـرار.

\section{مقوهات اختيار علم هصر : مقدران}

\section{أولاً : على المستوى المحلي (داخل مصر)}

علهم مصر بألوانه متعارف عليه على مستوى المجتمع طبقا للتصنيف التالي :

1- على مستوى المراحل التعليميـة : يرفع علهم مصر مـع طابور الصباح الذي يصاحبه نشيد الوطن فِ المرحلة الابتدائية والإعدادية والثانوية، وعندما تأتي مرحلة الجامعة وما بعد التخرج يكون ابن الوطن قد عرف وعشق رمز بلده "العله" وغار عليه حيث تعاملهه مـ العلم مِ الاحتفالات التي يهر بها المجتمـع من مناسبات قومية. r- على المستوى السياسي : يرفع عله الانتصار بعد الحروب، وعند الاستقبال الدولي، وأثناء عزف السلام الجمهوري، كما يلف بـه الشهيد. 


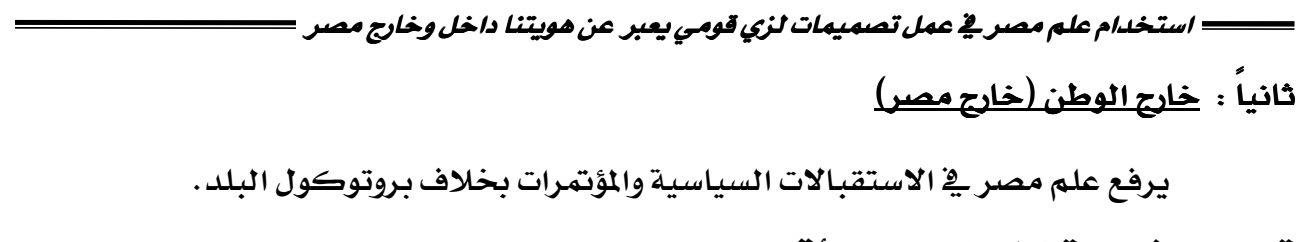

\section{تصميم الزي وارتباطه باللون والبيئة :}

إن هناك تذوقاً ودلالة عامة للون بِّ البيئة، فهناك تشابه للون بعناصره من الناحية

النفسية، والاجتماعية، والثقافية، والجمالية. كما أن للون دلالات ترتبط بتأثيرات ذات قيم تشكيلية تتعلق بعله الجمال، وسيكولوجية أي تأثير اللون على نفسية الإنسان، وفسيولوجية أي تأثير اللون

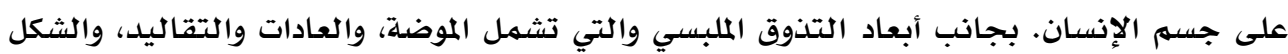
الجمالي (التزين) حيث تتوافر الألوان المألوفة (جذانب الانسان الانتباه).

\section{تصنيف الوظائف أو المهز التي تثثل مصر في الداخل والخارج:}

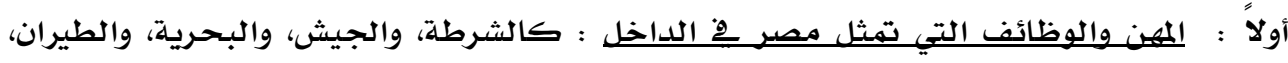
والسفارات والقنصليات، والكشافة، والجوالة، والرياضة بمراكزها وتصنيفاتها، والفرق

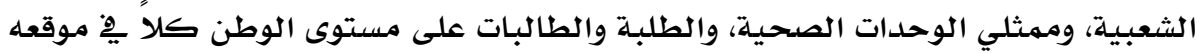

$$
\text { حيث يمثل واجهة مصروالوطن. }
$$

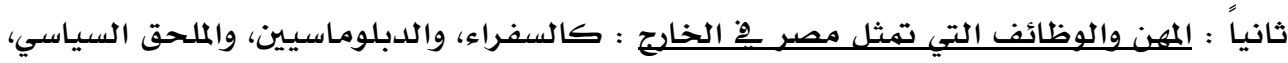
وموظفي شركات الطيران، والمصريين بالخارج، وممثلي الوطن. فهي عنوان المجتمع بكل فئاته ومستوياته، حيث تنوع الملابس والتصميمات للنساء والرجال والأطفال بما يتمشى مـع الموضة منها : بدلة، تايور، بالطو، جاكيت، كاب، سالوبيت، بنطلون، بلوزة، قميص، صديري، جيليه،

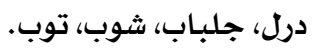

تذكر مقدمة البحث أنها عندما اختارت بعض المهن سواء داخل مصر أو خارجها يِّ عمل أزياء لهم من علم مصر حيث أنها وجدت من الصعوبة الكبرى توحيد الزي لجميـع أفراد المجتهـع وهي

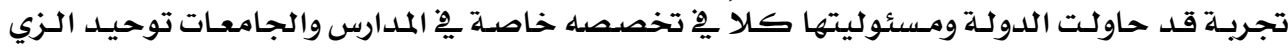

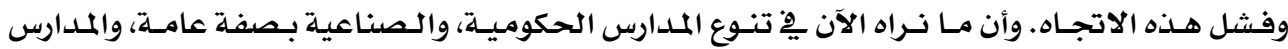
الخاصة بصفة خاصـة يِّ ألوان الزي ممـا جعل هنـالك أهواء لا نعرف مصدرها المقنع يِّ فوضى ألوان

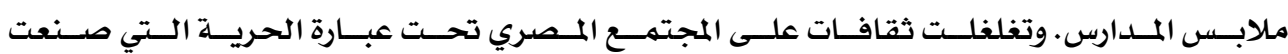

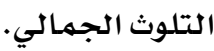




\section{الدراسة الإيدانية \\ دليل العمل الميداني}

عند وضـع الأسئلة تم مراعاة أن تكون الأسئلة موجهة لشرائح من المجتمـع بالتصنيف الآتي :

- شرائح من الجنسين لم ينالوا حظ من التعليه، والوظائف المختلفة. - شرائح من المثقفين بأعمار ووظائف مختلفة. - الجنسـين من المتعلمـين بأعمار مختلفة. - الأطفال من الجنسين منذ مرحلة الحضانة حتى الجـامعة. - الجنسين من المهن، والوظائف ذات الواجهة للوطن يِّ الداخل والخارج ولهم دور فعال يِّ الإعلام. أسئلة الدليل :

$$
\begin{aligned}
& \text { - هل هناك زي يعبر عن الهوية المصريةٌ؟ ما شكله؟ } \\
& \text { - من المسئول عن عدم وجود زي يعبر عن الهوية حتى الآن؟ } \\
& \text { - هل تشكل العادات والتقاليد دور ِِ السعي لعمل زي قومي مصري؟ } \\
& \text { - ما هو اقتر احك للفئة التي ترتدي الزي وتكون واجهة المجتمع؟؟ } \\
& \text { - ما رأيك مِّْ عمل زي من علم مصر وهل هناك بديل؟ } \\
& \text { - هل هناك وظائف أو مهن يمكن أن ترتدي الزي المصمهم من علم مصر؟ }
\end{aligned}
$$

- كيف يهكن إقناع المجتهع ِِِ القضاء على الآراء السلبية التي تسعى وراء الموضلة، ومحو

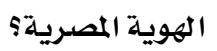

- هل الاحتلال الذي غزا مصر لكه دور ِِّ عدم وجود زي قومي؟ كيف؟ - هل هناك علاقة بين دور المجتمـع كمسئول من الناحية السياسية، ودور المتخصص كمصمهم يف تجاهل عمل زي يعبر عن الهويـة المصريـة؟ هئ دور - هل هناك ارتباط بين ثقافة المجتمع بصفة عامهة وثقافته فِ عمل زي قومي يحمل الهوية المصرية هِّ داخل وخارج الوطن كعنوان أعلامي؟ - كيف يصور الإعلام مصر كهوية ليس لها زي مناظرة لباقي الدول؟ - مـا هو الشكل الرسمي لمصر عند تمثيلها يِّا المؤتمرات والندوات خارج الوطن لمصر دون زي قومي؟ 
- ما هو مبررك عند حضورك مناسبات رسمية داخل أو خارج مصر وصعوبـة الإعلان عن هويتك

$$
\text { كلآخر يف عدم وجود زي قومي مصري؟ }
$$

وقد تبين من تحليل الأسئلة أن هناك جذور لمصر ممثلة يف العادات والتقاليد. وأن هناك شريحة كبيرة من المجتمع تدعو إلى الرغبة يْ الحاجـة لعمل زي قومي يعبر عن الهوية المصرية. ومن هذا المنطلق يعد البحث رؤية مستقبلية للتأكيد على دور المجتمـع بفئاته ووطنيته يِ جعل مصر واجهة للعحا لهم بصور عديدة. نتأج البمثث :

- استخدام علهم مصر مِّ عمل زي قومي من علم مصر يعبر عن الهوية المصرية وليس هناك بديل فِ

$$
\text { الوقت الحالي. }
$$

- عمل زي من علهم مصر يعد شكل إعلامي بصفة عامـة وللدول التي لا تعرف عن مصر شـيئًا بـصفة خاصـة. - - دعوى بعض أصحاب المصانع يِ تنفيذ الأزياء المصممة بمعايير الجودة والشكل الجمالي بما يحقق الهدف. - ما زالت هناك رواسب ثقافية تغزو بعض أفراد المجتمع لعدم عرض قضية فكرة علم مصر لتصميهم زي قومي يعبر عن الهويـة المصرية حيث لا يستهان بذلك.

\section{توضوهيـات :}

- عمل لجنة لحصر التصميمات المقترحة والمشاركة يِّار الرأي. - عمل ندوات، ودورات للشباب والأجيال الصاعدة من جهة، ومن خلال المدارس، والجامعات من جهة أخرى لمحارية غزو ثقافات الملابس الوافدة والتي تتعارض مـع ثقافتنا والدعوة لعمل زي قومي. إتاحة الفرصدة للمستلهمـين، والمتخصصين ِِ عمل تصميمات يتوافر فيها الإبداع، والابتكار من علهم مصر. - تدعيهم الاهتمام بعمل زي قومي من علهم مصر بتصميمات لمن يمثل مصر مِِ الداخل والخارج من خلال ندوات ومحاضرات والدعوة للجهات التالية للاهتمام:O الكليات المتخصصدة والمهتمـة بالأزياء والملابس. O كليات الاقتصاد المنزلي. 


$$
\begin{aligned}
& \text { O كليات الفنون التطبيقية (قسم الملابس- الموضدة...) } \\
& \text { O كليات التربية النوعية. } \\
& \text { O مراكز الموضدة. }
\end{aligned}
$$

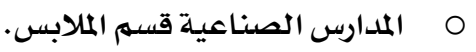

$$
\begin{aligned}
& \text { O م الأسر المنتججة. } \\
& \text { O مصور الثقافة. }
\end{aligned}
$$

\section{المراجـ ع}

- دوزي - زاينهارات - المعجم المفصل بأسماء الملابس عند العرب - ترجمة أكرم فاضل -

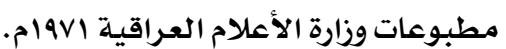

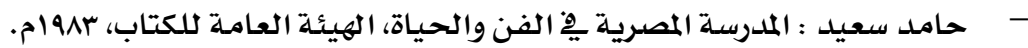

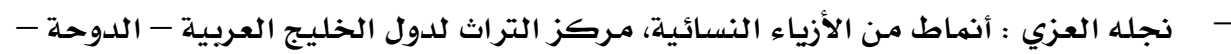

قطر 19v0م.

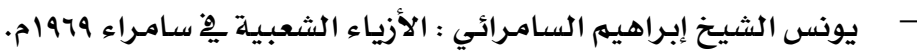

- يحيي حمودة :الألوان- القاهرة - دارومطابع الشعب، ديسمبر 1970 ام.

- Edward Lame: Manners \& Customs of Modern: Egyptian Everyone Library, 1963, Egyptian.

- Patrick John: "Fashion Design" Published by B.T.Btas Ford, Ltd, London, 1997.

- Lehnert Gertrud: "A History of Fashion in the $20^{\text {th }}$ Century" Lucille for Creation Services, Ltd., London, 2000.

- Luence Vorfe: "Fashion and Costumes" Mac.Milan Publishing Co., Inc, 1990. 


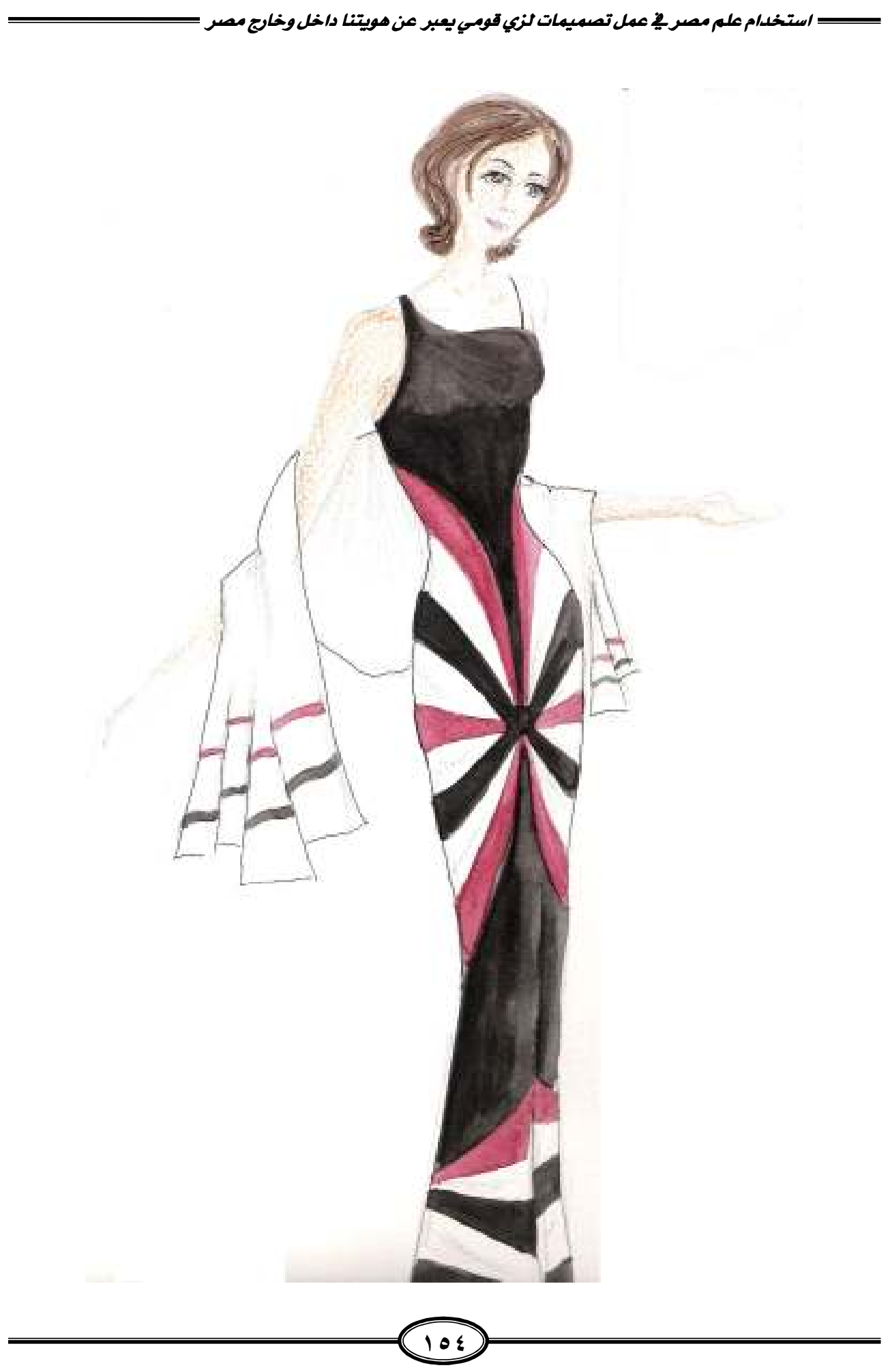




$$
\text { 负 }
$$




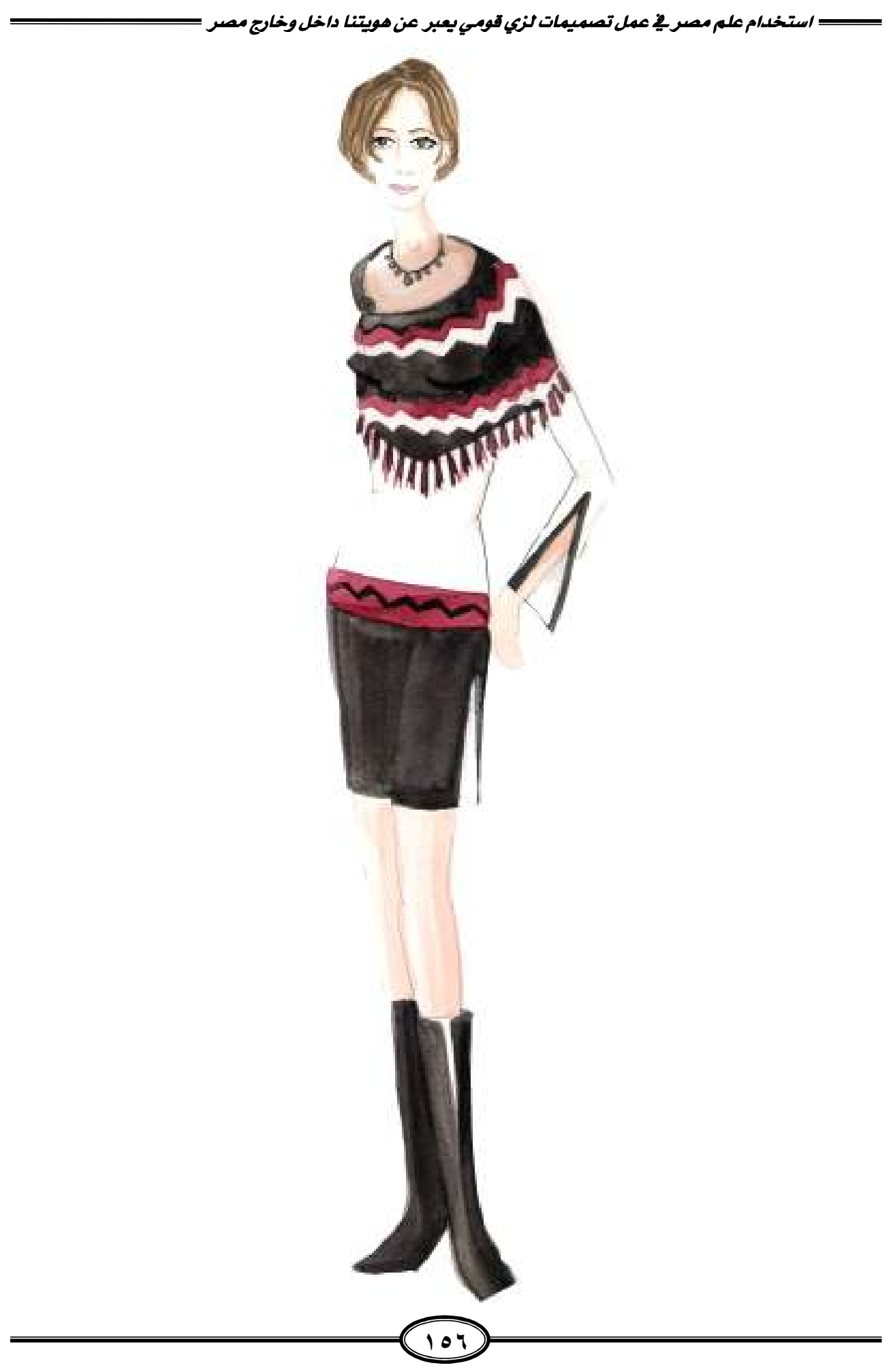




$$
\text { 㑒 }
$$




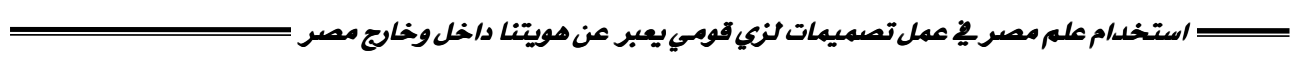

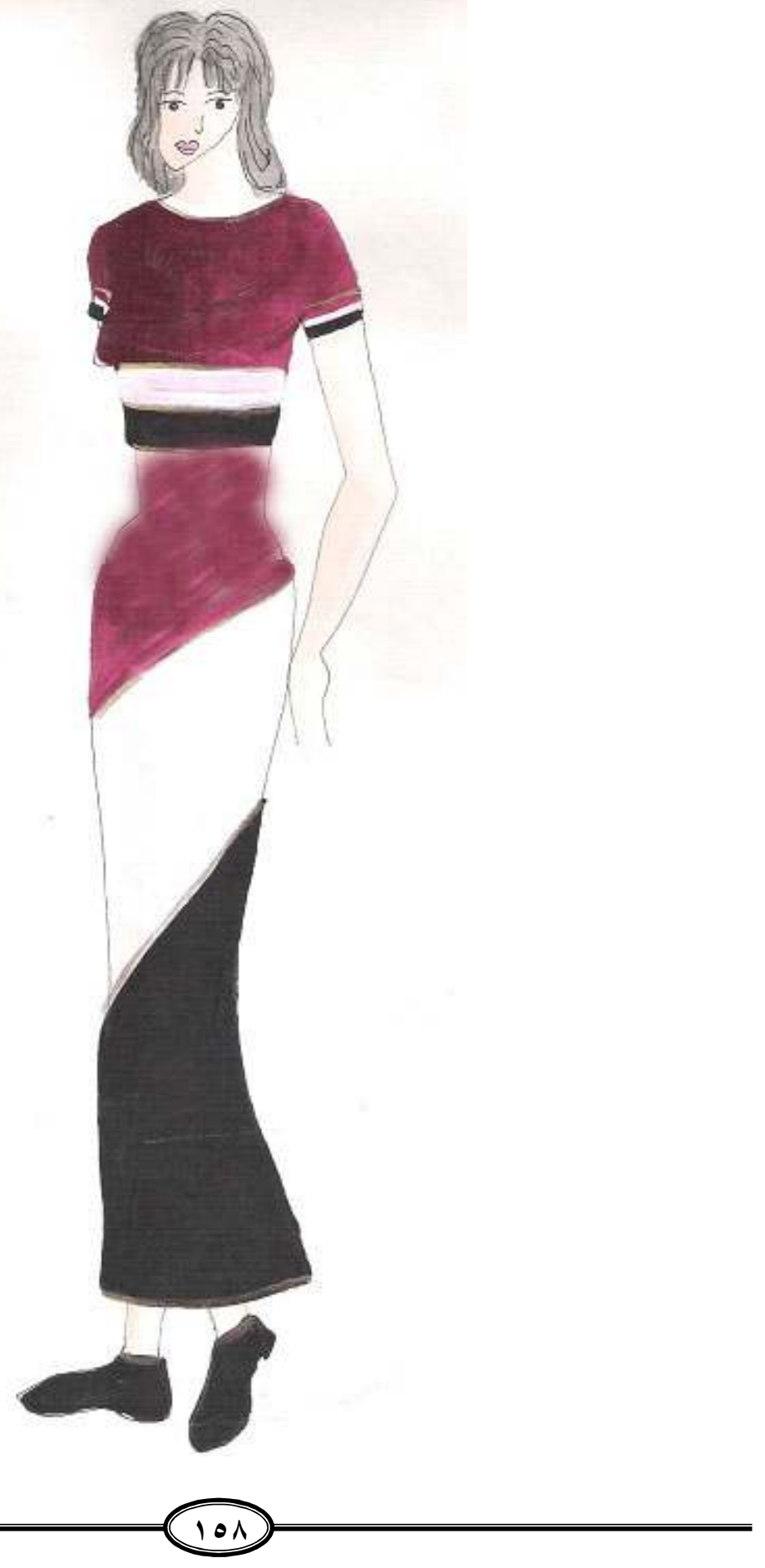




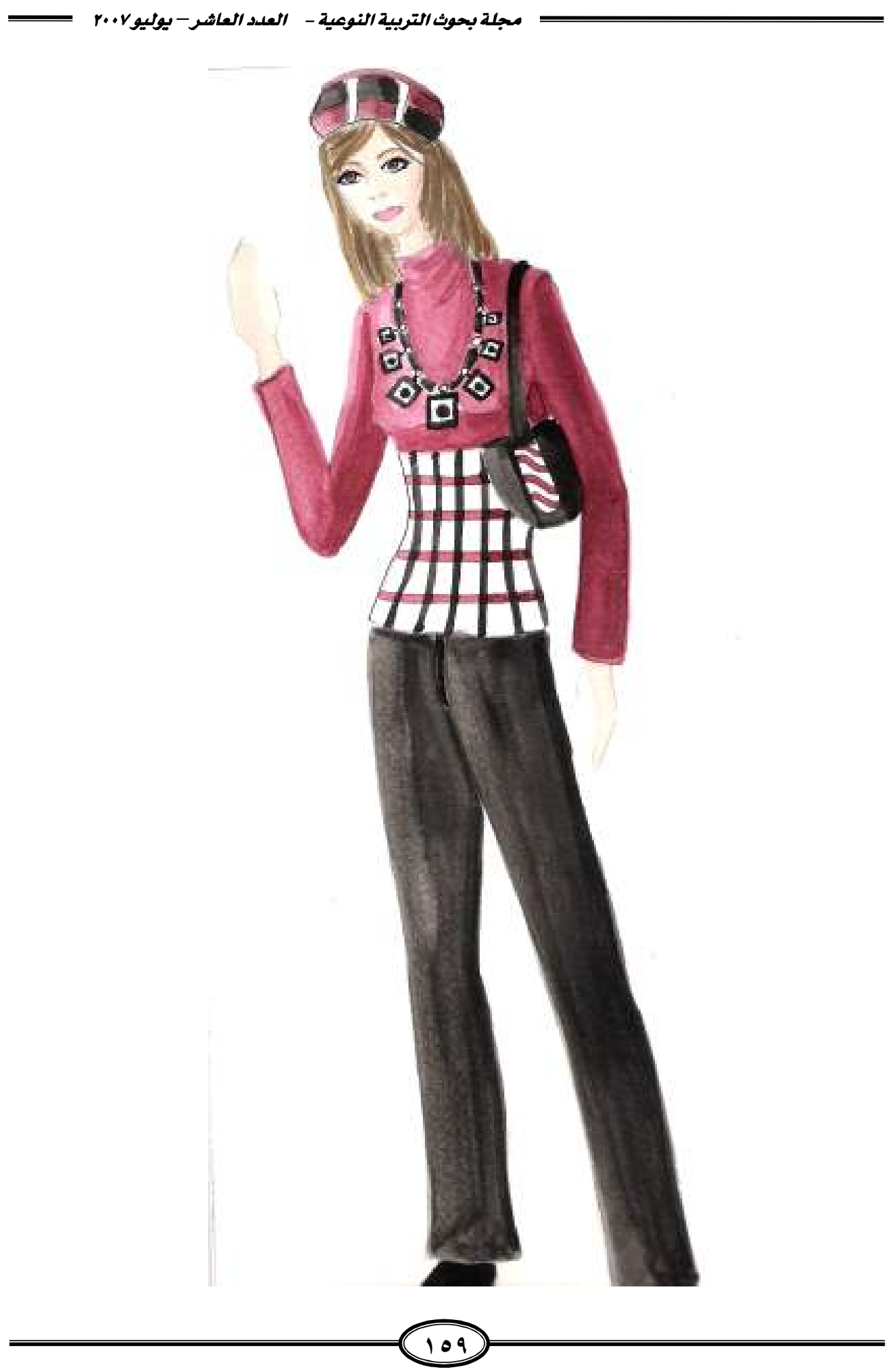




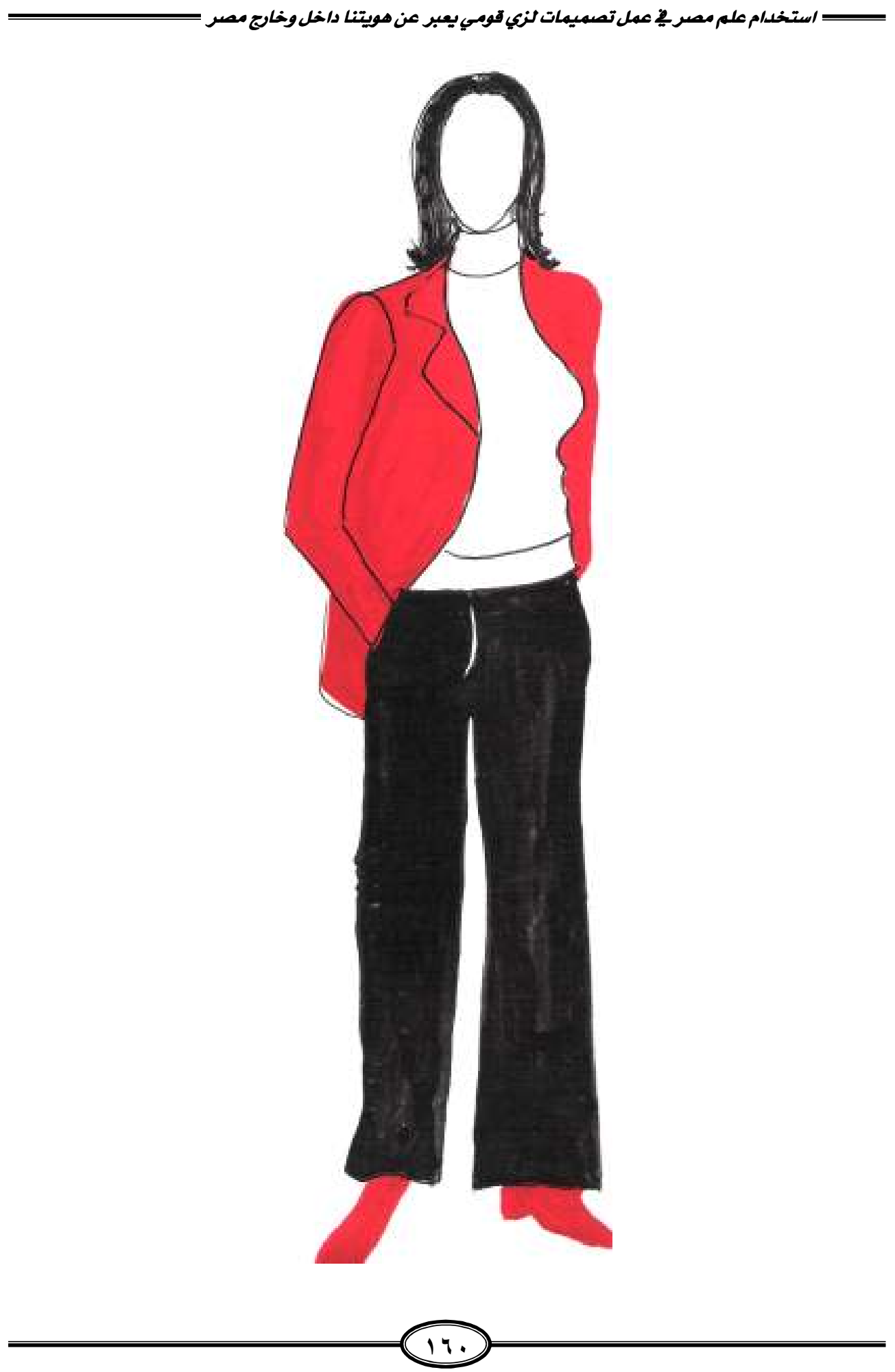




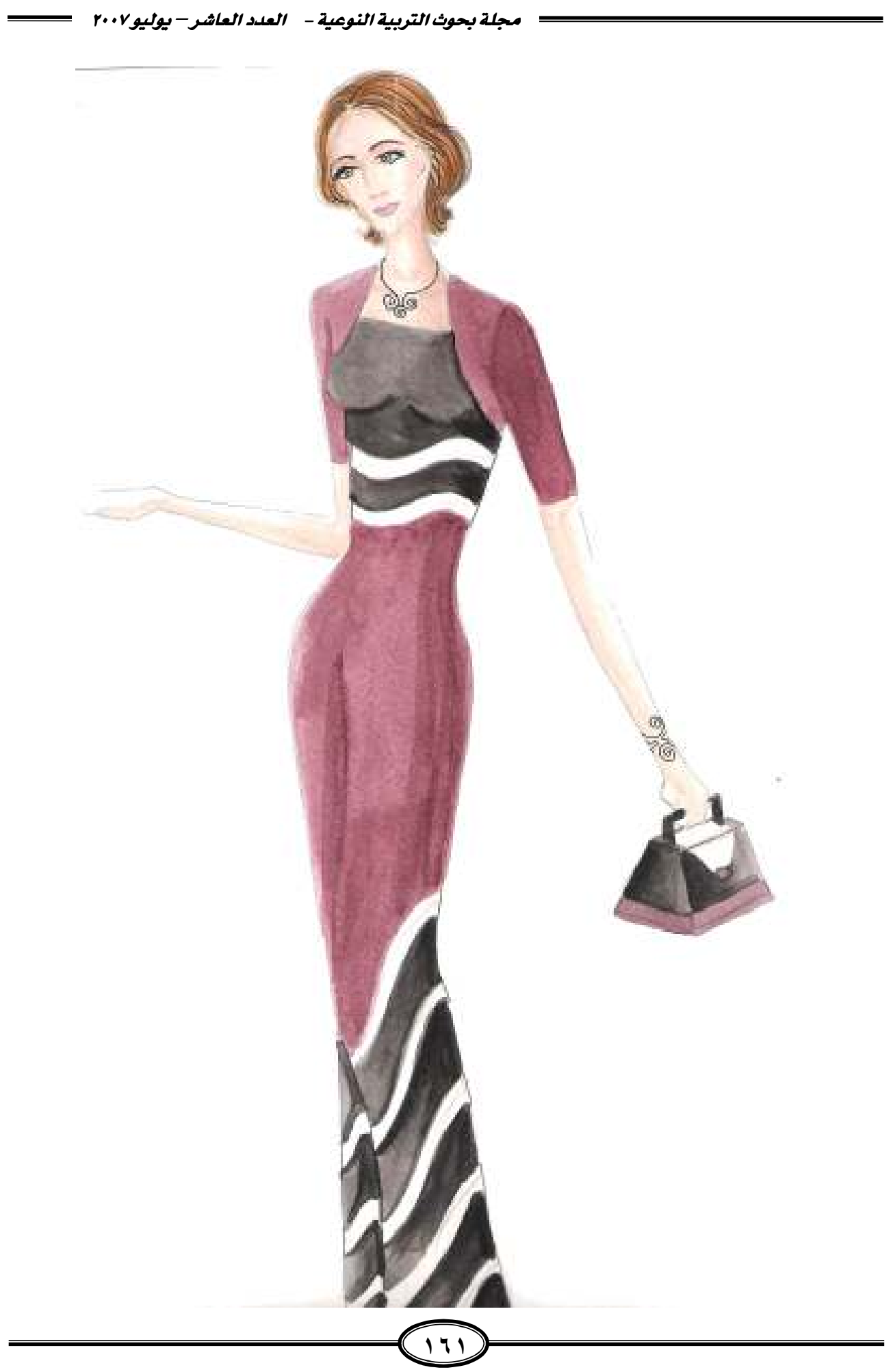




$$
=
$$





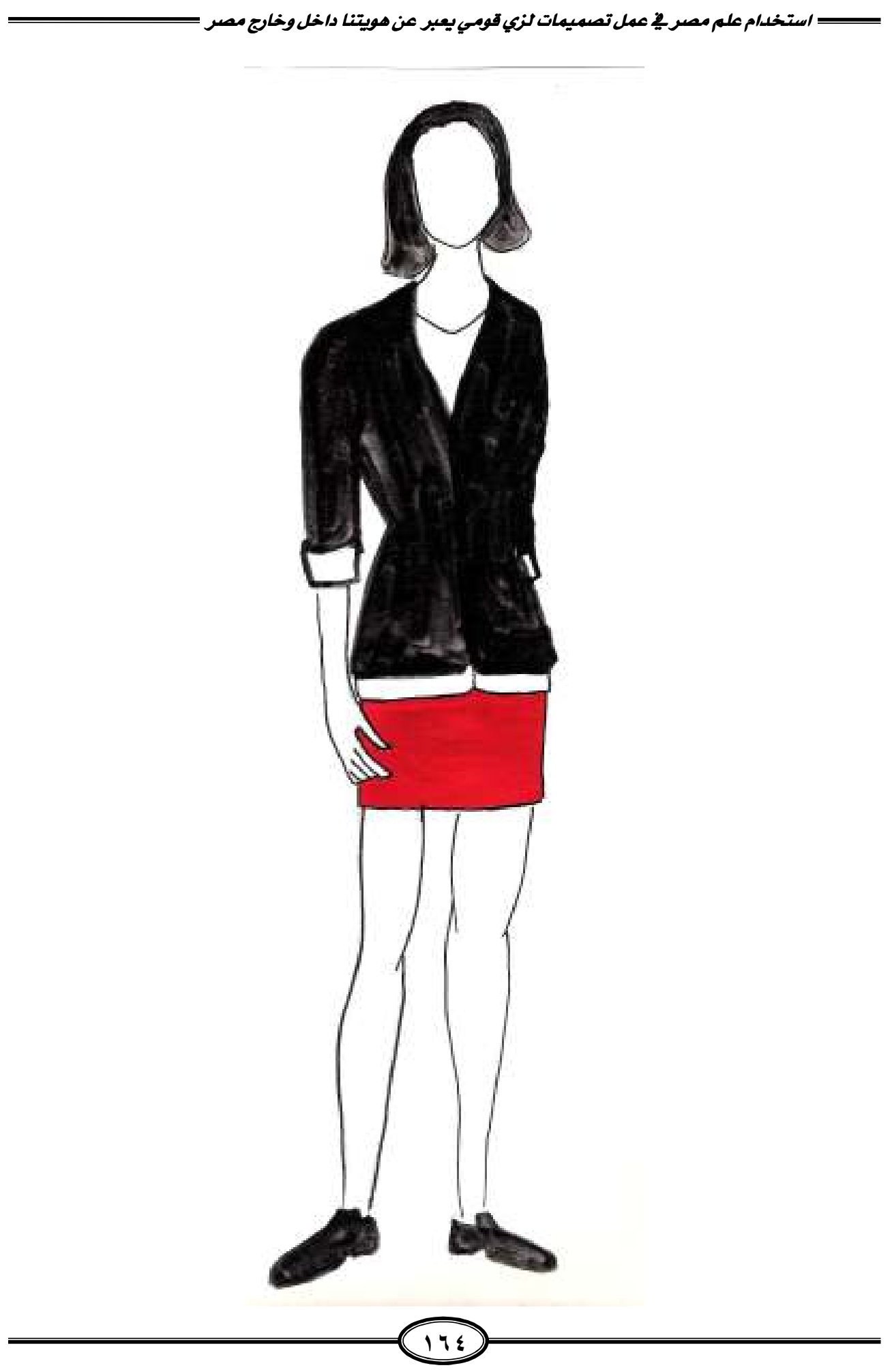




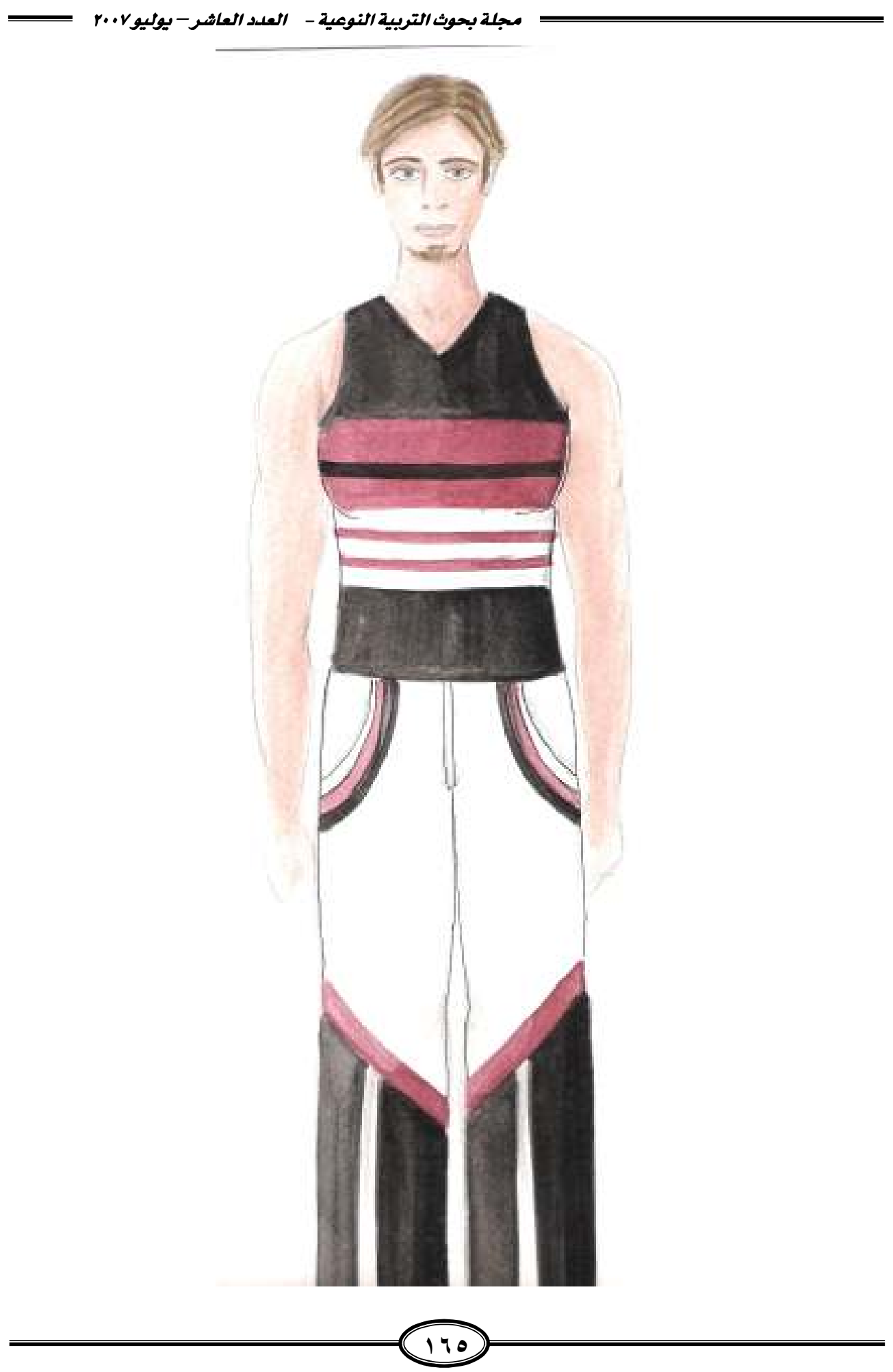




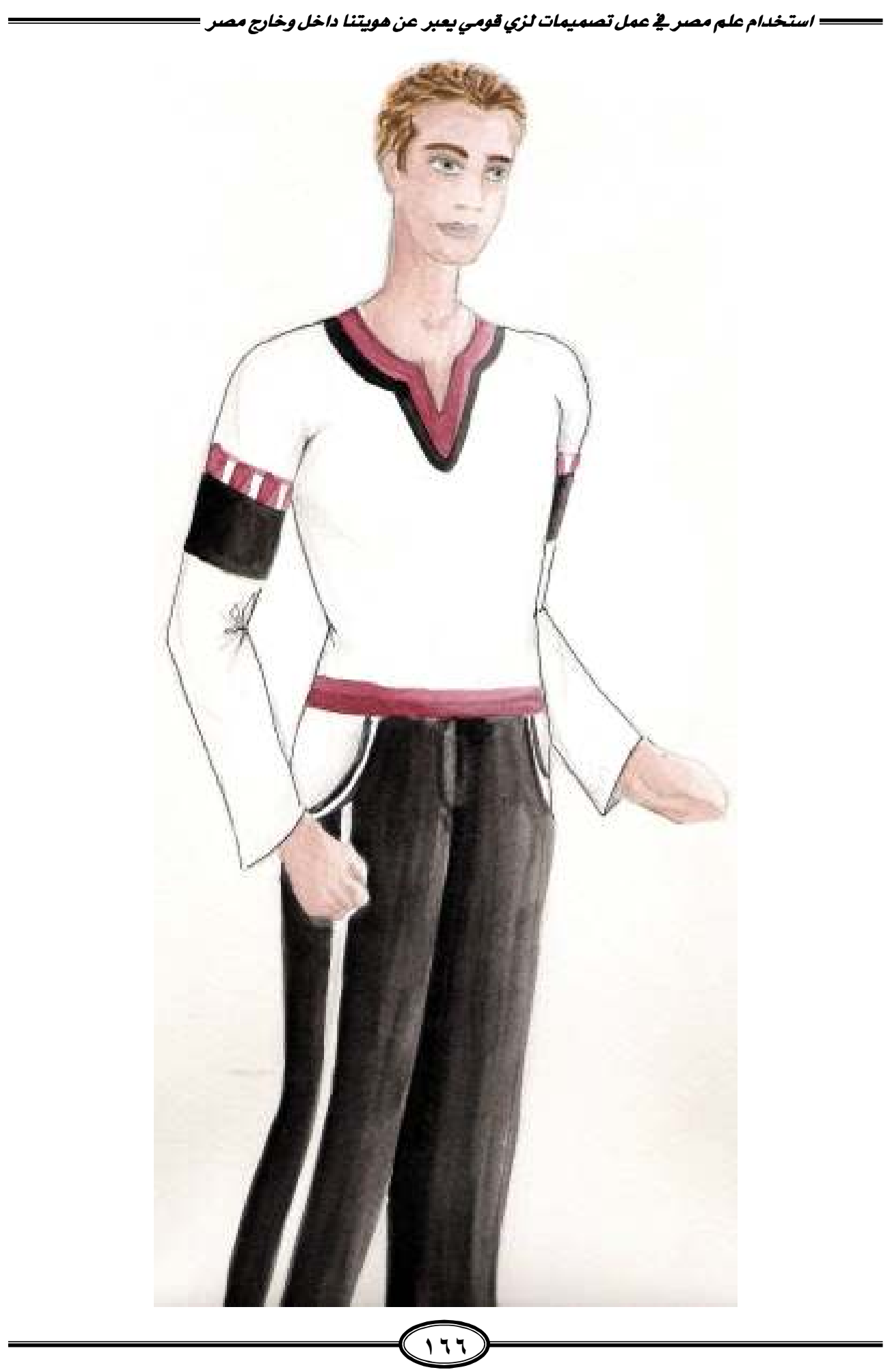




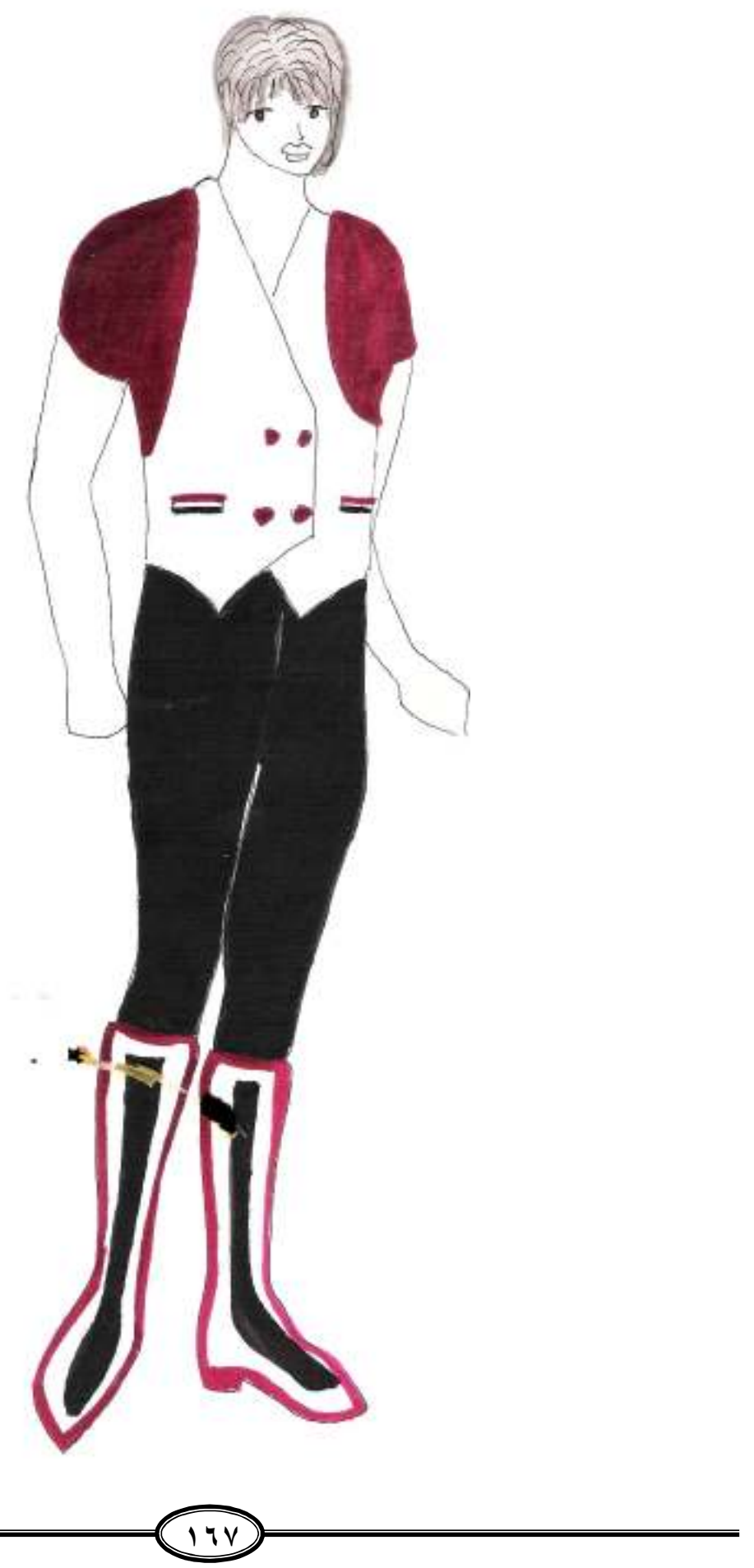




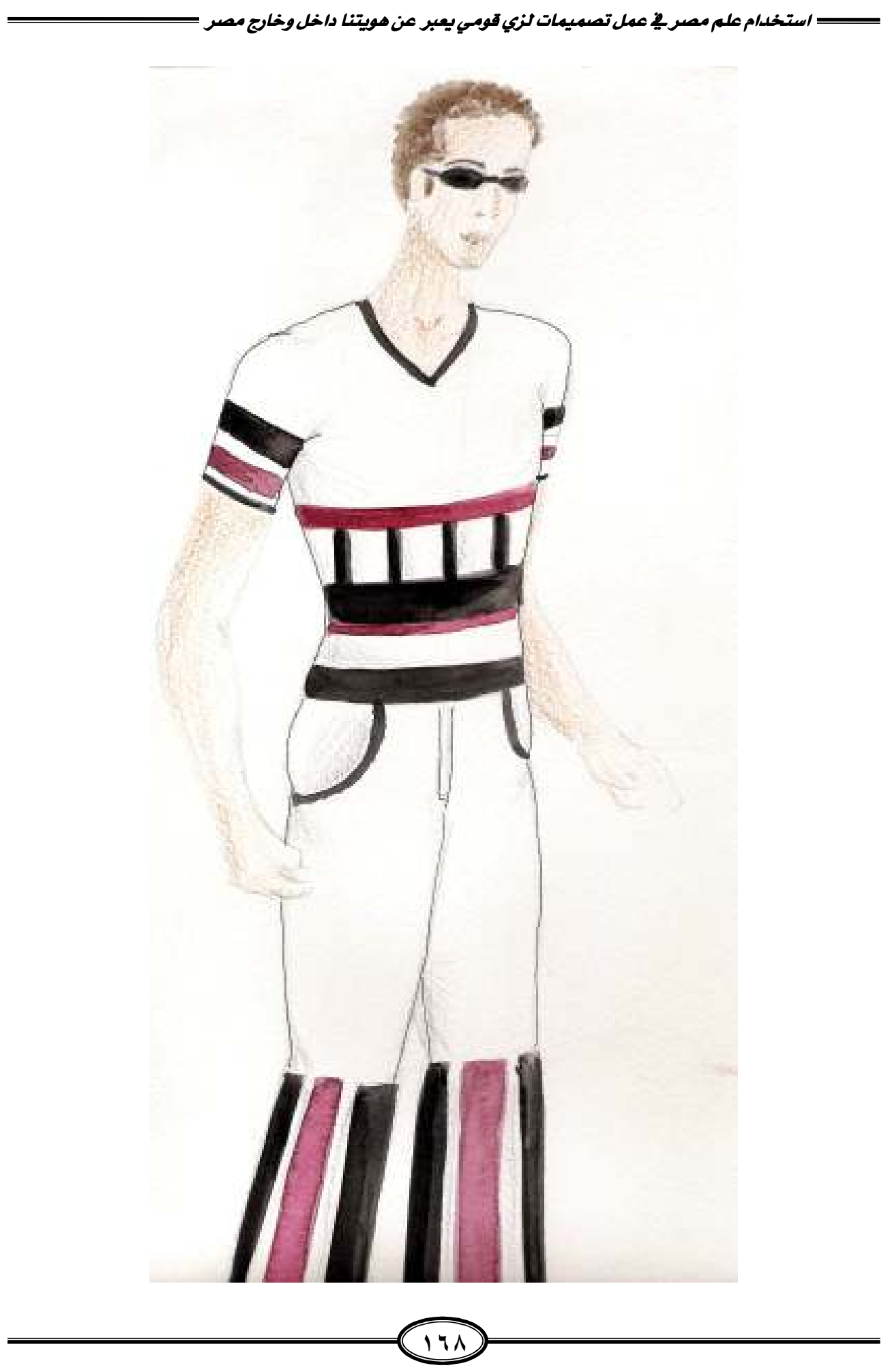

